\title{
Polar alicyclic rings: Synthesis and structure of all cis-1,2,3,4- tetrafluorocyclopentane
}

\author{
Zeguo Fang, , Nawaf Al-Maharik, Alexandra M. Z. Slawin, ${ }^{a}$ Michael Bühl, and David O'Hagan. ${ }^{\text {** }}$ \\ Receipt/ Acceptance Data [DO NOT ALTER/DELETE THIS TEXT] \\ 5 Publication data [DO NOT ALTER/DELETE THIS TEXT] \\ DOI: 10.1039/b000000x [DO NOT ALTER/DELETE THIS TEXT]
}

The all-cis isomer of 1,2,3,4-tetrafluorocyclopentane is prepared and characterised by NMR and X-ray crystallography and the experimental structure compared with theory. The structure has

10 a similarly high polarity to all-cis tetrafluorocyclohexanes despite the increased conformational flexibility of a cyclopentane.

Recently we reported the synthesis and analysis of cyclohexanes containing four ${ }^{1,2}$ or six fluorine ${ }^{3}$ atoms each with only one fluorine on each carbon, and with the fluorines configured stereochemically

15 such that all of the fluorine atoms are 'up' or cis to each other. The structures 1-3 are illustrated in Figure 1. These all-cis fluorinated cyclohexanes are perhaps unexpectidly solid materials at room temperature. Eg all cis-1,2,3,4-tetrafluorocyclohexane $\mathbf{1}$ has a melting point of $83{ }^{\circ} \mathrm{C}$ and a calculated dipole moment of $\mu=4.91 \mathrm{D}$ and the

20 all cis-1,2,4,5-isomer 2 has a melting point of $106{ }^{\circ} \mathrm{C}$ and a dipole moment of $\mu=5.24 \mathrm{D}$. The high melting points and polarity arise because of the polarity induced by having 1,3 diaxial $\mathrm{C}-\mathrm{F}$ bonds in the chair conformation of the cyclohexane rings, the C-F bond being the most polar covalent bond to carbon. ${ }^{4}$ In the case of all cis-

25 1,2,3,4,5,6-hexafluorocyclohexane $3{ }^{3}$ there are three axial C-F bonds in the chair conformation, and this molecule has a melting point of $206{ }^{\circ} \mathrm{C}$ and a calculated dipole moment of $\mu=6.2 \mathrm{D}$, the highest recorded for an aliphatic compound. ${ }^{3}$<smiles>FC1CCC(F)C(F)C1F</smiles>

1<smiles>FC1CC(F)C(F)CC1F</smiles>

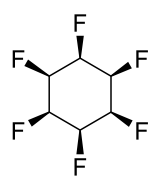

3

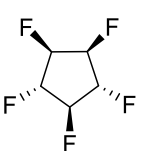

30 There is a general interest in polar organofluorine aliphatics in performance materials such as liquid crystals $^{5}$ for displays or piezoelectric materials for electrical devices such as actuators. ${ }^{6} \mathrm{New}$ motifs that might enhance exploration into these areas are desirable. As an extension of our investigation into the small polar cyclohexane

35 rings 1-3 containing cis-vicinally arranged fluorines, we have begun to explore cyclopentanes with appropriately configured C-F bonds. Cyclopentanes are conformationally more flexible than cyclohexanes, ${ }^{7}$ and it was of interest to determine if we could prepare an all-cis, vicinally substituted cyclopentane and how ordered such a 40 system would be in both the solution and solid state.

${ }^{a}$ University of St Andrews, School of Chemistry and Centre for Biomolecular Sciences, North Haugh, St Andrews, Fife, KY16 9ST, UK Fax: 01334 463800; Tel: 01334 467171; E-mail: do1@st-andrews.ac.uk † Electronic Supplementary Information (ESI) available: [details of any supplementary information available should be included here]. See

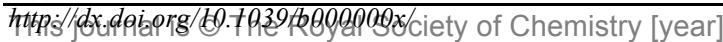

Monofluorocyclopentane is well known ${ }^{8}$ and cis- and trans- 1,2difluorocyclopantanes have been prepared. ${ }^{9}$ There are no examples of vicinal fluorinated tri- or tetra- cyclopentanes in the literature. Intriguingly there is a report ${ }^{10}$ from 1966 of the preparation and 45 characterisation of a single stereoisomer 4 of 1,2,3,4,5pentafluorocyclopenane. This compound was isolated as a low level component $(0.5 \%)$ from the $\mathrm{CoF}_{3}$ fluorination of cyclopentane. However isomer $\mathbf{4}$ is of a stereochemistry where polarity is compromised, because there are fluorines on both sides of the ring. 50 Cyclopentane 4 is a liquid (bp $109-110^{\circ} \mathrm{C}$ ) at room temperature and pressure rather than a solid material expected of a more polar ring system. In this Communication we report the synthesis of all-cis 1,2,3,4-tetrafluorocyclopentane $\mathbf{5}$, with the four fluorines arranged on one face of the cyclopentane. The synthesis of $\mathbf{5}$ exploited a protocol 55 of Suzuki et al.," for the conversion of freshly cracked cyclopentadiene $\mathbf{6}$ to cis-diepoxide $\mathbf{8}$, via endoperoxide $\mathbf{7}$ as illustrated in Scheme 1.
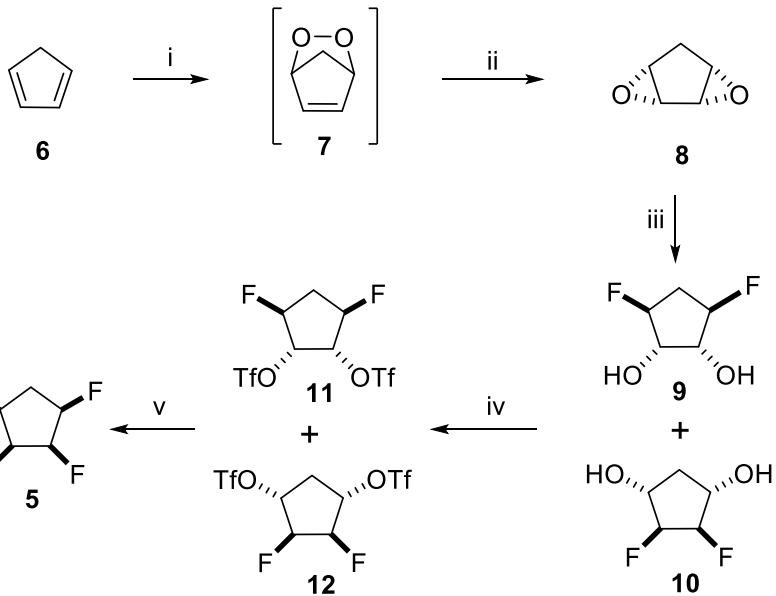

Scheme 1. Synthesis of tetrafluorocyclopentane 5 (i) $\mathrm{O}_{3}, \mathrm{P}(\mathrm{OPh})_{3}$, $60 \mathrm{CH}_{2} \mathrm{Cl}_{2},-78^{\circ} \mathrm{C}, 38 \%$; (ii) $\mathrm{Ru}\left(\mathrm{PPh}_{3}\right)_{3} \mathrm{Cl}_{2}, \mathrm{CH}_{2} \mathrm{Cl}_{2},-78^{\circ} \mathrm{C}, 1 \mathrm{~h} ;-40{ }^{\circ} \mathrm{C}, 0.5 \mathrm{~h}$; $-25^{\circ} \mathrm{C}, 1 \mathrm{~h}$; (iii) $\mathrm{Et}_{3} \mathrm{~N} \cdot 3 \mathrm{HF}, 120^{\circ} \mathrm{C}, 24 \mathrm{~h}$; (iv) $\mathrm{Tf}_{2} \mathrm{O}$, pyridine, $\mathrm{RT}, 24 \mathrm{~h}$; (v) $\mathrm{Et}_{3} \mathrm{~N} \cdot 3 \mathrm{HF}, 100{ }^{\circ} \mathrm{C}, 48 \mathrm{~h}, 9 \%$ over steps (iii) $-(\mathrm{v})$.

Ring opening of the epoxides was accomplished using $\mathrm{Et}_{3} \mathrm{~N} \cdot 3 \mathrm{HF}^{12}$ to 65 generate a mixture of regioisomers $9 / 10$. Triflation of the free alcohols (mix of isomers) generated 11/12 and then treatment of the triflates with $\mathrm{Et}_{3} \mathrm{~N} .3 \mathrm{HF}^{13}$ gave a sample of $\mathbf{5}$. Cyclopentane $\mathbf{5}$ was indeed isolated as a solid although with a melting point of $39^{\circ} \mathrm{C}$ and it was noticably volatile and sublimed on standing over a period of a

70 few days at ambient temperature. As a consequence it proved challenging to isolate $\mathbf{5}$ in significant quantities by chromatography. None-the less analytical samples were secured in sealed flasks and a suitable crystal was used for single crystal analysis. The resultant structure of $\mathbf{5}$ is shown in Figure 1. 75 

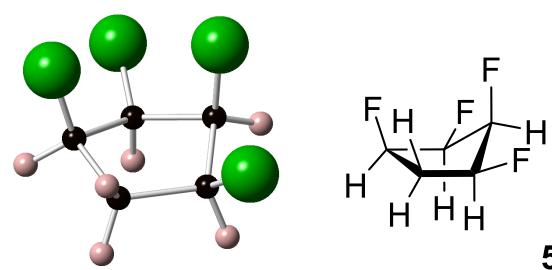
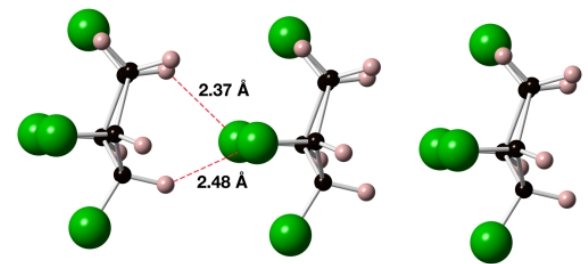

80 Figure 1. X-Ray structure of 5. Upper image shows an isolated structure. The lower image shows four molecules linearly stacked with fluorine 11 faces pointing to adjacent hydrogen faces consistent with electrostatic ordering. The distances highlighted are the shortest intermolecular 85 CF ${ }^{\cdots} \mathrm{HC}$ contacts

The molecular ordering in the solid state (bottom of Figure 1) clearly illustrates the facial polarity of cyclopentane $\mathbf{5}$, a characteristic which was observed for the all-cis fluorinated cyclohexanes 1-3. ${ }^{1-3}$ The molecules of 4 stack one on top of each

90 other perpendicular to the ring plane (four molecules are shown

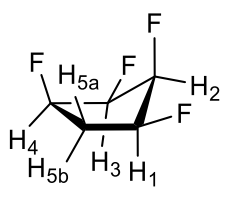

5

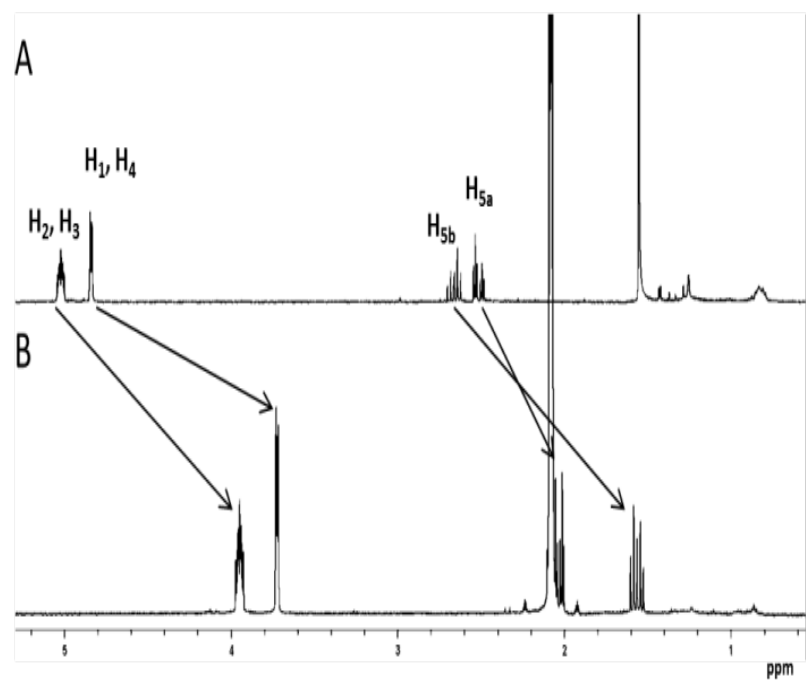

\begin{tabular}{|c|c|c|c|}
\hline $\begin{array}{c}\text { Proton } \\
\text { signal }\end{array}$ & $\begin{array}{c}\delta \mathrm{CDCl}_{3} \\
(\mathrm{ppm})\end{array}$ & $\begin{array}{r}\delta\left[{ }^{2} \mathrm{H}_{8}\right]-\text { Toluene } \\
(\mathrm{ppm})\end{array}$ & $\begin{array}{c}\Delta \delta \\
(\mathrm{ppm})\end{array}$ \\
\hline $\mathrm{H}_{5 \mathrm{a}}$ & 2.51 & 2.03 & +0.48 \\
\hline $\mathrm{H}_{5 \mathrm{~b}}$ & 2.66 & 1.56 & +1.10 \\
\hline $\mathrm{H}_{2}, \mathrm{H}_{3}$ & 4.84 & 3.77 & +1.12 \\
\hline $\mathrm{H}_{1}, \mathrm{H}_{4}$ & 5.02 & 3.95 & +1.10 \\
\hline
\end{tabular}

1305

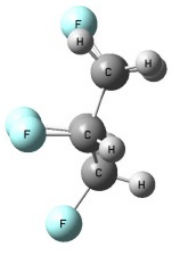

$5 a$

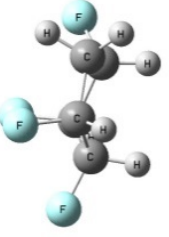

$5 \mathbf{a}$
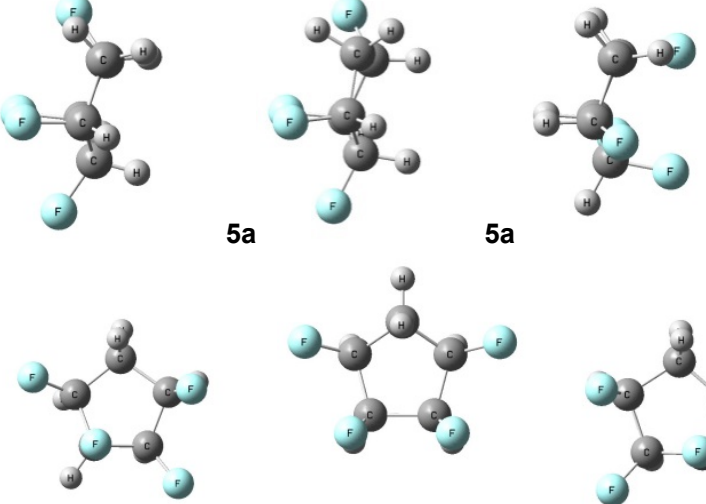

$5 a$

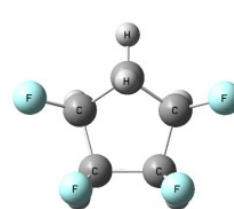

$5 \mathrm{~b}$

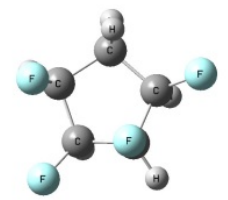

Figure 3. Calculated structures of 5 (B3LYP-D3/6-311+G(d,p) level of theory); at the top left the X-ray structure, 5a is the sole minimum in 135 different orientations (5a' its mirror image).

Optimisations starting from all possible unique permutations of the $\mathrm{F}$ and $\mathrm{H}$ atoms in an envelope form of $\mathbf{5}$ converged to one and the same minimum, 5a (Figure 3). This minimum is slightly 140 twisted from the structure in the solid state (compare $\mathbf{5}$ and $\mathbf{5 a}$ in the top left of Figure 3). Although relatively small, this twist affords another envelope conformer, but now with the $\mathrm{F}$ atom at the tip of the envelope in an axial, rather than an equatorial position (compare the two structures 5a in the top right of Figure

145 3; these are identical, but shown in different orientations). This small distortion occurs irrespective of the level of theory (other 
DFT functionals, MP2 level) or the environment (gas phase, a second molecule stacked on top or a polarisable continuum 205
model). For an estimate of the energetic effect of this 150 conformational twist, we performed a partial optimisation freezing the conformation of the $\mathrm{C}_{5}$ ring to that observed in the solid (by fixing the C-C-C-C dihedral angles) and relaxing all other structural parameters. The resulting structure of $\mathbf{5}$, denoted 21 $\mathbf{5}$ (fix), is $2.2 \mathrm{kcal} / \mathrm{mol}$ higher in energy than the fully optimised

155 minimum 5a. It may be that the structure in the crystal is affected by packing forces. A single molecule carved out of the crystal has a higher computed dipole moment $(5.8 \mathrm{D})$ than the minimum $\mathbf{5 a}$ (4.9 D, B3LYP-D3 level, see Figure S1 in the ESI for a plot of 215 the electrostatic potential), which would serve to reinforce the

160 stacking shown in Figure 1.

Two of the alternative envelope forms (with a $\mathrm{CH}_{2}$ group at the envelope tip) can be optimised imposing $C_{\mathrm{s}}$ symmetry. Essentially isoenergetic, they are not minima but transition states with a single imaginary frequency each, involved in the

165 rearrangement of $\mathbf{5 a}$ with its mirror image, $5 \mathbf{a}^{\prime}$. One of these transition states, $\mathbf{5 b}$, is depicted at the bottom of Figure 3. The computed barrier for this pseudorotation-type rearrangement is $\Delta H^{\ddagger}=2.5 \mathrm{kcal} / \mathrm{mol}$ at room temperature. This very low value is consistent with the apparent $C_{\mathrm{s}}$ symmetry on the NMR time scale225 5 .

170 and the failure to detect any line broadening even at temperatures as low as $-80^{\circ} \mathrm{C}$.

Table 1: Selected computed $J(\mathrm{H}, \mathrm{H})$ coupling constants (in $\mathrm{Hz}$ ), BHandH/6-311+G(2d,p)//B3LYP-D3/6-311+G(d,p) level.

\begin{tabular}{|c|c|c|c|c|}
\hline & $\mathrm{H}_{5 \mathrm{a}}-\mathrm{H}_{5 \mathrm{~b}}$ & $\mathrm{H}_{5 \mathrm{a}}-\mathrm{H}_{1,4}{ }^{a}$ & $\mathrm{H}_{5 \mathrm{~b}}-\mathrm{H}_{1,4}{ }^{a}$ & MAD $^{b}$ \\
\hline $\operatorname{Expt}^{c} 5$ & 16.3 & 4.3 & 7.4 & n.a. \\
\hline Calc. 5a & -15.1 & 4.5 & 7.6 & 0.5 \\
\hline Calc. 5(fix) ${ }^{d}$ & -15.8 & 1.8 & 7.6 & 1.1 \\
\hline Calc. $\mathbf{5 b}$ & -10.9 & 10.8 & 5.6 & 5.5 \\
\hline
\end{tabular}

$175{ }^{a}$ Mean value of couplings to $\mathrm{H}_{1}$ and $\mathrm{H}_{4}$ (See Table $\mathrm{S} 1$ in the Supporting Information for individual values). ${ }^{b}$ Mean absolute 240 deviation from experiment [absolute values used for $J\left(\mathrm{H}_{5 \mathrm{a}}, \mathrm{H}_{5 \mathrm{~b}}\right)$ ]. ${ }^{c}$ Experimental data (this work, $\mathrm{CDCl}_{3}$ ). ${ }^{d}$ Partially optimised 180 structure with $\mathrm{C}_{5}$ conformation as observed in the solid.

Indirect spin-spin coupling constants involving the $\mathrm{CH}_{2}$ group have been computed at the BHandH/6-311+G(2d,p) level. ${ }^{16}$ The results collected in Table 1 clearly show that the apparent $C_{\mathrm{s}}$ symmetry on the NMR time scale cannot arise from a static $C_{\mathrm{s}^{-}}$

185 symmetric structure such as $\mathbf{5 b}$, because this shows large deviations between observed and computed $J(\mathrm{H}, \mathrm{H})$ values. Good agreement is obtained for the averaged couplings in both fully and partially optimised structures (assuming fluxional motion as discussed above); incidentally the values computed for the fully 255

190 optimised minimum 5a fit slightly better to experiment than those for 5 (fix), with mean absolute deviations of $0.5 \mathrm{~Hz}$ and $1.1 \mathrm{~Hz}$, respectively (see rightmost column in Table 1). These data thus support the interpretation that the dominant conformation in solution may be closer to the pristine minimum 5a than the

195 structure found in the solid state.

In conclusion we have prepared cyclopentane $\mathbf{5}$ and demonstrated experimentally by X-ray structure analysis in the solid state and by NMR analysis in solution, that it has highly polarised faces.

200 Theory studies indicate fluxionality with a low barrier for pseudorotation, to the extent that the precise conformation observed in the solid may be different from that of the pristine molecule in the gas phase or in solution. The calculated molecular dipole moment of minimised conformations is large 55.0 D placing this cyclopentane in a similar and very polar catergory to that of the more conformationally defined cyclohexanes 1-2. It follows that functionalised all-cis tetrafluorocyclopentanes would offer an interesting new motif for the design of performance molecules extending from organic 10 materials to medicinal or agrochemicals research.

Acknowledgements: We are grateful to the Chinese Scholarship Council for Studentship support (ZF), to EPSRC for financial support and to the EPSRC National Mass Spectrometry Service at 15 Swansea for analytical support. DO'H thanks the Royal Society for a Wolfson Research Merit Award.

\section{References}

1. A. J. Durie, A. M. Z. Slawin, T. Lebl, P. Kirsch, D. O’Hagan, Chem. Commun., 2011, 47, 8265 - 8267.

220 2. A. J. Durie, A. M. Z. Slawin, T. Lebl, P. Kirsch, D. O’Hagan, Chem Commun, 2012, 48, 9643-9645.

3. N. S. Keddie, A. M. Z. Slawin, T. Lebl, D. Philp, D. O’Hagan Nature Chemistry, 2015, 7, 483-488.

4. D. O'Hagan, Chem. Soc. Rev., 2008, 37, $308-319$.

(a) M. Bremer, P. Kirsch, M. Klasen-Memmer, K. Tarumi, Angewandte, Chemie, Int. Ed., 2013, 52, 8880-8896; (b) P. Kirsch, M. Bremer, ChemPhysChem., 2010, 11, 357-360.

6. (a) T. Zeng, R. Claus, Y. Liu, W. Du, K. L. Cooper, Smart Mater. Struct., 2000, 9, 801 - 804; (b) G. M. Sesslar, J. Acoust. Soc. Am., 1981, 70, 1596 - 1608; S. Horiuchi, Y. Tokura, Nature Materials., 2008, 7, $357-366$.

7. E.L. Eliel, S.H. Wilen and L.N. Mander, 'Stereochemistry of Organic Compounds', Wiley, New York, 1994.

8. (a) N. P. Mankad, F. D. Toste, Chem. Sci., 2012, 3, 72-76; (b) V. A. Petrov, S. Swearingen, W. Hong, W. C. Petersen, J. Fluorine Chem., 2001, 109, 25-31.

9. (a) D. F. Shellhamer, A. A. Briggs, B. M. Miller, J. M. Prince, D. H. Scott, V. L. Heasley, J. Chem. Soc., Perkin Trans. 2, 1996, $973-$ 977; (b) M. Hudlicky, J. Fluorine Chem., 1987, 36, 373 - 384; (c) A. Baklouti, R. El Gharbi, J. Fluorine Chem., 1979, 13, 297 - 314;

10. A, Bergomi, J. Burdon, T. M. Hodgins, R. Stephens, J. C. Tatlow, Tetrahedron, 1966, 22, 43-51.

11. M. Suzuki, H. Ohtake, Y. Kameya, N. Hamanaka, R. Noyori, J. Org. Chem., 1989, 54, $5292-5302$.

245 12. D. Wölker, G. Haufe, J. Org. Chem. 2002, 67, 3015 - 3021.

13. A. J. Durie, T. Fujiwara, R. Cormanich, M. Bühl, A. M. Z. Slawin, D. O'Hagan, Chem. Eur. J., 2014, 20, 6259-6263.

14. (a) J. D. Dunitz, R. Taylor, Chem. Eur. J., 1997, 3, 89 - 98; (b) J.A.K. Howard, V. J. Hoy, D. O'Hagan, G. T. Smith, Tetrahedron, 1996, 52, 12613-12622.

15. M. J. Corr, R. A. Cormanich, C. N. von Hahmann, M. Bühl, D. B. Cordes, A. M. Z. Slawin, D. O'Hagan, Org. Biomol. Chem. 2016, 14, 211-219.

16. Similar levels have been found to perform well for this property, see a.g.: (a) T. Kupka, Magn. Reson. Chem., 2009, 47, 674. (b) R. Suardíaz, C. Pérez, R. Crespo-Otero, J. M. García de la Vega, J. San Fabián, J. Chem. Theor. Comput., 2008, 4, 448 
